Am J Prev Med. 2009 November ; 37(5): 468-471. doi:10.1016/j.amepre.2009.06.020.

\title{
Ending the Epidemic of Heterosexual HIV Transmission Among African Americans
}

\author{
Adaora A. Adimora, MD, MPH, Victor J. Schoenbach, PhD, and Michelle A. Floris-Moore, \\ MD \\ School of Medicine (Adimora, Floris-Moore), and UNC Gillings School of Global Public Health \\ (Adimora, Schoenbach), University of North Carolina at Chapel Hill, Chapel Hill, North Carolina
}

\begin{abstract}
This article examines factors responsible for the stark racial disparities in HIV infection in the U.S. and the now concentrated epidemic among African Americans. Sexual network patterns characterized by concurrency and mixing among different subpopulations, together with high rates of other sexually transmitted infections, facilitate dissemination of HIV among African Americans. The social and economic environment in which many African Americans live shapes sexual network patterns and increases personal infection risk almost independently of personal behavior. The African American HIV epidemic constitutes a national crisis whose successful resolution will require modifying the social and economic systems, structures, and processes that facilitate HIV transmission in this population.
\end{abstract}

\section{Introduction}

African Americans' HIV prevalence is an order of magnitude greater than the prevalence among whites. ${ }^{1}$ The racial disparity in HIV prevalence has persisted in the face of both governmental and private actions, involving many billions of dollars, to combat HIV. This article examines factors that contribute to the marked racial disparity in heterosexually transmitted HIV infection in the U.S. and the now concentrated epidemic among African Americans. The disparity has resulted in large part from the socioeconomic environment in which many African Americans live. The situation requires urgent, determined, and specific actions to modify the underlying structural determinants that have led to HIV's substantial inroads in African American communities.

(C) 2009 American Journal of Preventive Medicine. Published by Elsevier Inc. All rights reserved.

Address correspondence and reprint requests to: Adaora A. Adimora, MD, MPH, University of North Carolina School of Medicine, Division of Infectious Diseases, 130 Mason Farm Road, CB \#7030, Chapel Hill, North Carolina 27599-7030. adimora@ med.unc.edu..

Publisher's Disclaimer: This is a PDF file of an unedited manuscript that has been accepted for publication. As a service to our customers we are providing this early version of the manuscript. The manuscript will undergo copyediting, typesetting, and review of the resulting proof before it is published in its final citable form. Please note that during the production process errors may be discovered which could affect the content, and all legal disclaimers that apply to the journal pertain.

No financial disclosures were reported by the authors of this paper. 


\section{Racial Disparities}

The marked racial disparities in HIV/AIDS in the U.S. have been documented in surveillance data and studies in special populations, such as men who have sex with men, injection drug users, job corps entrants, and childbearing women. The CDC estimates that $45 \%$ of new HIV infections in the U.S. in 2006 occurred among non-Hispanic blacks. ${ }^{2}$ The few HIV seroprevalence data that are available for the general U.S. population confirm the extent of HIV dissemination among African Americans. Among the 13,184 adolescents and young adults in The National Longitudinal Study of Adolescent Health (Add Health), a nationally representative study, HIV seroprevalence was almost $0.5 \%$ among blacks -20 times that of whites. ${ }^{3}$ The National Health and Nutrition Examination Surveys (NHANES), which surveyed a national sample of U.S. adults in households in 1999-2002, reported HIV seroprevalences of $1.9 \%$ for black men and $1.01 \%$ for black women aged 18-39 years, and $2.8 \%$, and $4.5 \%$, respectively, for black women and men aged $40-49$ years. ${ }^{4}$ Updated NHANES estimates report similar results. ${ }^{1}$

These estimates of HIV prevalence among African Americans are strikingly similar to, and in some cases exceed, population-based estimates of HIV seroprevalence among adults, age 15 through 49, reported by several countries in subSaharan Africa, Asia, and the Caribbean. ${ }^{5}$ Although individual-level sexual behaviors contribute to the disparity in HIV prevalence, observed differences in individual behaviors do not fully explain the marked racial differences in HIV infection prevalence. ${ }^{6}$ HIV prevalence among African Americans exceeds that of whites, typically substantially, even in comparisons stratified by education, poverty index, marital status, age at first sexual intercourse, lifetime number of sex partners, history of male homosexual activity, illicit drug use, injection drug use, and HSV-2 antibody positivity. ${ }^{4}$

\section{Contributors to Higher HIV Prevalence}

HIV disseminates throughout the population through the combined impact of individual behaviors and biological and population-level factors. Other STIs, such as syphilis, Chlamydia, gonorrhea, and genital herpes, facilitate HIV transmission, and the prevalence of these STIs is much greater among African Americans. ${ }^{7,8}$ The population attributable risk of HSV-2 and other STI for sexual transmission of HIV among African Americans is therefore substantial. ${ }^{9}$ It is unclear how much other biological factors contribute to the racial disparity in HIV infection rates. A 32-base pair deletion in the chemokine receptor 5 gene, rare in whites and considerably less common in blacks, ${ }^{10}$ decreases susceptibility to HIV infection. ${ }^{11}$ Male circumcision decreases men's risk of acquiring HIV infection through vaginal intercourse. ${ }^{12}$ African American men are less likely to be circumcised (73\%) than U.S. white men $(88 \%){ }^{13}$

Sexual networks, at the nexus between individuals and the larger population, are key factors in the spread of STI. The extent of sexual mixing among subpopulations at different risk for infection is an important parameter for population dissemination. Compared to whites, blacks with few sex partners are more likely to have sexual contact with individuals who have many partners, a type of dissortative mixing that spreads infection to more subgroups within a population. ${ }^{14}$ Because of racially segregated mixing patterns and the much higher 
HIV seroprevalence in African Americans, exposure to the virus is more likely among blacks than among whites for any given number of partners or frequency of sexual contacts.

Concurrent sexual partnerships (relationships that overlap in time) can spread infection through a sexual network faster than the same rate of acquisition of new, sequential relationships. ${ }^{15}$ This partnership pattern has been associated with transmission of STIs, including HIV infection acquired through heterosexual activity. ${ }^{16}$ The prevalence of concurrent partnerships is higher among U.S. blacks than whites. ${ }^{17,18}$ Lower marriage rates among African Americans appear to be a major contributing factor. Incarceration is also associated with concurrency. ${ }^{19}$ The extent of concurrency probably contributes significantly to HIV transmission among African Americans. ${ }^{19}$

\section{Contextual Factors}

Exogenous factors including economic forces, demographic features, and other structural aspects of society that are beyond individual control influence sexual behaviors, sexual network features, and spread of STI. Racial discrimination is a common denominator of several important aspects of the social and economic context for many African Americans, such as poverty, the low ratio of men to women, de facto racial segregation, and disproportionate incarceration. These pathways have been previously discussed in depth ${ }^{19}$ and are briefly summarized below.

Poverty, a reality of life for a disproportionately large number of African Americans, is strongly associated with HIV infection (see, for example ${ }^{20}$ ). Poverty influences where one lives, can lead to housing instability, decreases healthcare access, and destabilizes relationships; all of these influences can affect sexual networks. Widespread residential segregation by race, as well as racial segregation and re-segregation of schools, concentrates poverty and other adverse social and economic influences among blacks, increasing their risk of socioeconomic failure, ${ }^{21}$ and altering social and sexual networks of both adults and youth. The population gender ratio (number of men: women) is a major determinant of the structure of sexual networks and marital patterns. ${ }^{22}$ High male mortality has lowered the gender ratio among African Americans, which likely influences not only marriage rates, but also participation in sexual risk behaviors and sexual mixing and other network patterns. Disproportionate incarceration of black men further reduces the gender ratio, increases poverty, and influences sexual networks and mixing patterns.

\section{Structural Violence}

The overall impact of the contextual factors outlined above constitutes structural violence, a social system characterized by inequalities in power and life chances of sufficient magnitude to restrict a group of people from realizing their full potential ${ }^{23}$ and put them "in harm's way". ${ }^{24}$ (p 1686) The system is structural because it is "embedded in the political and economic organization of our social world" and "violent because it causes injury to people (typically, not those responsible for perpetuating such inequalities)." ${ }^{24}$ (p 1686) Although the link between social context and disease is increasingly recognized, with a few notable exceptions (see for example, ${ }^{25,26}$ ), the specific role of structural violence in the HIV epidemic among African Americans has received considerably less research attention. 
There are various reasons for this relative neglect. First, epidemiology tends to focus on individual-level risk factors, which are more amenable to studies using standard epidemiologic methods, more readily modifiable, and can in principle be modified by individuals even without organized social action. Second, a focus on individual-level factors "resonates with the value and belief systems of Western culture that emphasize [the individual's ability to control] his or her personal fate and the importance of doing so."27 Third, structural violence, by its very nature, is so deeply entrenched that it is rendered ordinary and almost invisible. ${ }^{23,24}$ Fourth, although epidemiologists and other public health researchers are increasingly studying contextual factors, there remains the question of how to devise effective interventions to alter the context.

\section{A New Public Health Research and Intervention Paradigm}

The reasons for the nation's failure to control the epidemic among African Americans include the prevailing paradigm for HIV research and prevention. This paradigm has emphasized individual-level interventions while neglecting the systems, structures, and processes that facilitate HIV.25 Such a focus ignores the knowledge that social forces contribute to disease rates in the population and that the social and economic environment affects personal behaviors. Highly efficacious individual-level interventions could have a population-level impact, but by the end of 2008, only 4 of 31 completed RCTs had demonstrated significant efficacy in preventing sexual transmission of HIV.28

Although a comprehensive plan is not being presented here, several areas are obvious targets for immediate attention. First, the paucity of national HIV seroprevalence data that can be used to monitor the level of the epidemic in major population groups is a critical deficiency in the public health response to the epidemic. The Add Health and NHANES surveys have demonstrated that national HIV seroprevalence surveys are now feasible. Seroprevalence data are an essential tool for monitoring the epidemic, maintaining awareness of its extent, and bringing it under control.

Second, the dramatic escalation of the war on drugs starting in the 1970s, with the imposition of lengthy, mandatory sentences, has resulted in huge growth of the incarcerated population and enormous collateral damage. Although the racial disparity in sentencing due to the different penalties for possession of crack and powder cocaine is finally being ended, with the unanimous 2007 decision of the U.S. Sentencing Commission, racial inequities in sentencing for other crimes persist and require attention. Investments in disadvantaged children (e.g., enriched preschools, home visitation programs, better trained teachers) and adults (e.g., literacy programs, educational opportunities, workforce development, consumer and legal assistance, mental health services, reintegration programs for released prisoners, drug courts) can reduce crime and improve economic productivity, realizing positive economic returns. The heavy reliance on incarceration to control the drug and crime problems has stressed state budgets and decreased spending for other essential programs, such as education. ${ }^{29}$ The current economic crisis increases the saliency of this issue. Feasible alternatives to incarceration for nonviolent offenders should be sought; some states have now begun to pursue strategies to curb prison growth and costs. ${ }^{30}$ Third, policies and laws must be evaluated concerning their effects on inequality, defacto segregation, and 
racial discrimination. Elimination of homelessness and provision of adequate housing is also an important intervention strategy. A growing body of data shows that improved housing status is associated with reduction in HIV risk behavior as well as better health outcomes among HIV-infected people. Interventions that provide affordable, stable housing are effective strategies for HIV prevention and have proven to be cost saving, given the magnitude of the medical care costs associated with HIV infection. ${ }^{31}$

Fourth is a policy area of particular relevance to HIV prevention, sex education. The federal government has expended over $\$ 1.5$ billion on abstinence-only-until-marriage sex education over a period of nearly 3 decades, notwithstanding the lack of data to support the effectiveness of this education in reducing risky behavior. ${ }^{32}$ Over $80 \%$ of abstinence-only curricula used by grantees of the largest federal abstinence-only initiatives contained false, misleading, or distorted information about reproductive health, including efficacy of condoms for preventing infection. ${ }^{33}$ Youth who receive abstinence-only education are significantly less likely to perceive condoms as efficacious for preventing HIV and other STIs. ${ }^{33}$ In contrast, comprehensive sex education programs can be effective in reducing risky sexual behavior among youth. ${ }^{34}$ Federal and state government restrictions on sex education in schools should be removed, and funds allocated for curricula shown to be effective in reducing risks of infection and unintended pregnancy. Schools should provide comprehensive sex education that includes both encouragement for abstinence and accurate information concerning condom use and efficacy. ${ }^{35}$ Youth, particularly those at high risk for HIV infection, have a right to lifesaving sex education.

These four examples illustrate areas where societal-level changes can help to arrest the HIV epidemic among African Americans and where action can be taken immediately. However, implementation of these recommendations alone will not alter the underlying structural violence that promotes high disease rates among African Americans. There is accordingly a continuing need for development and evaluation of interventions-especially structural interventions - that address the underlying social determinants of the racial disparity in HIV infection in the U.S. Structural interventions that address social determinants have been shown to improve health and decrease disparities in other diseases. ${ }^{36}$ The current analyses suggest that such interventions and the positive changes they bring will likely increase stable monogamy in disadvantaged U.S. populations and thereby reduce the spread of HIV.

\section{Conclusion}

Continuing racial disparities in HIV infection more than 2 decades after the identification of the virus and availability of an accurate test are an indictment of the U.S. response to the epidemic. Existing interventions have failed to control the epidemic in African Americans in part because critical features of the socioeconomic context promote behaviors that transmit HIV and increase the risk of HIV infection even among those who do not have high-risk behaviors. Failure to address these structural determinants has allowed the epidemic to continue in the black community. There is a need for research and interventions that are informed by expertise in public health, medicine, basic science, and social sciences - along with expertise in economics, business and finance, education, criminal justice, political science, and other disciplines. Eliminating racial disparities in HIV infection will require 
policy changes such as the four recommend above—as well as broadening the research paradigm to address gross disparities in socioeconomic resources. Governments should be held accountable for progress or lack thereof in eliminating inequities.

\section{Acknowledgments}

We thank Dr. Paul A. Godley for his insightful comments and review of the manuscript. Financial support: National Institute of Child Health and Human Development (award 1R21HD054293-01A1 to A.A.A.).

\section{REFERENCES}

1. McQuillan, GM.; Kruszon-Moran, D. HIV infection in the United States household population aged 18-49 years: Results from 1999-2006. NCHS data brief no 4. National Center for Health Statistics; Hyattsville, MD: 2008.

2. Hall HI, Song R, Rhodes P, et al. Estimation of HIV incidence in the United States. Jama. 2008; 300(5):520-9. [PubMed: 18677024]

3. Morris M, Handcock MS, Miller WC, et al. Prevalence of HIV Infection Among Young Adults in the United States: Results From the Add Health Study. Am J Public Health. 2006; 96(6):1091-7. [PubMed: 16670236]

4. McQuillan GM, Kruszon-Moran D, Kottiri BJ, et al. Prevalence of HIV in the U.S. household population: the National Health and Nutrition Examination Surveys, 1988 to 2002. J Acquir Immune Defic Syndr. 2006; 41(5):651-6. [PubMed: 16652040]

5. UNAIDS. WHO. AIDS Epidemic Update: December 2007. Joint United Nations Programme on HIV/AIDS (UNAIDS) and WHO; Geneva, Switzerland: 2007.

6. Aral SO, Adimora AA, Fenton KA. Understanding and responding to disparities in HIV and other sexually transmitted infections in African Americans. Lancet. 2008; 372(9635):337-40. [PubMed: 18657713]

7. CDC. Trends in reportable sexually transmitted diseases in the United States, 2006. 2007.

8. Xu F, Sternberg MR, Kottiri BJ, et al. Trends in herpes simplex virus type 1 and type 2 seroprevalence in the United States. JAMA. 2006; 296(8):964-73. [PubMed: 16926356]

9. Wald A, Link K. Risk of human immunodeficiency virus infection in herpes simplex virus type 2seropositive persons: a meta-analysis. J Infect Dis. 2002; 185(1):45-52. [PubMed: 11756980]

10. Zimmerman PA, Buckler-White A, Alkhatib G, et al. Inherited resistance to HIV-1 conferred by an inactivating mutation in $\mathrm{CC}$ chemokine receptor 5: studies in populations with contrasting clinical phenotypes, defined racial background, and quantified risk. Molecular medicine (Cambridge, Mass. 1997; 3(1):23-36.

11. Liu R, Paxton WA, Choe S, et al. Homozygous defect in HIV-1 coreceptor accounts for resistance of some multiply-exposed individuals to HIV-1 infection. Cell. 1996; 86(3):367-77. [PubMed: 8756719]

12. Gray RH, Kigozi G, Serwadda D, et al. Male circumcision for HIV prevention in men in Rakai, Uganda: a randomised trial. Lancet. 2007; 369(9562):657-66. [PubMed: 17321311]

13. Xu F, Markowitz LE, Sternberg MR, Aral SO. Prevalence of circumcision and herpes simplex virus type 2 infection in men in the United States: the National Health and Nutrition Examination Survey (NHANES), 1999-2004. Sex Transm Dis. 2007; 34(7):479-84. [PubMed: 17413536]

14. Laumann EO, Youm Y. Racial/ethnic group differences in the prevalence of sexually transmitted diseases in the United States: A network explanation. Sex Transm Dis. 1999; 26:250-61. [PubMed: 10333277]

15. Morris M, Kretzschmar M. Concurrent partnerships and transmission dynamics in networks. Social Networks. 1995; 17:299-318.

16. Adimora AA, Schoenbach VJ, Martinson FE, et al. Heterosexually transmitted HIV infection among African Americans in North Carolina. J Acquir Immune Defic Syndr. 2006; 41(5):616-23. [PubMed: 16652036] 
17. Adimora AA, Schoenbach VJ, Doherty IA. Concurrent sexual partnerships among men in the United States. Am J Public Health. 2007; 97(12):2230-7. [PubMed: 17971556]

18. Adimora A, Schoenbach V, Bonas D, Martinson F, Donaldson K, Stancil T. Concurrent Sexual Partnerships among Women in the United States. Epidemiology. 2002; 13:320-7. [PubMed: 11964934]

19. Adimora AA, Schoenbach VJ. Social context, sexual networks, and racial disparities in rates of sexually transmitted infections. J Infect Dis. 2005; 191(Suppl 1):S115-22. [PubMed: 15627221]

20. Krueger LE, Wood RW, Diehr PH, Maxwell CL. Poverty and HIV seropositivity: the poor are more likely to be infected. AIDS. 1990; 4(8):811-4. [PubMed: 2261136]

21. Massey, DS.; Denton, NA. American Apartheid: Segregation and the making of the underclass. Harvard University Press; Cambridge, MA: 1993.

22. Guttentag, M.; Secord, P. Too Many Women: The Sex Ratio Question. Sage; Beverly Hills: 1983.

23. Galtung J. Violence, Peace, and Peace Research. Journal of Peace Research. 1969; 6(3):167-91.

24. Farmer PE, Nizeye B, Stulac S, Keshavjee S. Structural violence and clinical medicine. PLoS medicine. 2006; 3(10):e449. [PubMed: 17076568]

25. Blankenship KM, Friedman SR, Dworkin S, Mantell JE. Structural interventions: concepts, challenges and opportunities for research. J Urban Health. 2006; 83(1):59-72. [PubMed: 16736355]

26. Lane SD, Rubinstein RA, Keefe RH, et al. Structural violence and racial disparity in HIV transmission. J Health Care Poor Underserved. 2004; 15(3):319-35. [PubMed: 15453172]

27. Link BG, Phelan J. Social conditions as fundamental causes of disease. J Health Soc Behav. 1995:80-94. Spec No. [PubMed: 7560851]

28. Weiss HA, Wasserheit JN, Barnabas RV, Hayes RJ, Abu-Raddad LJ. Persisting with prevention: The importance of adherence for HIV prevention. Emerging themes in epidemiology. 2008; 5:8. [PubMed: 18620578]

29. The Pew Charitable Trusts. One in one hundred: Behind bars in America in 2008. The Pew Charitable Trusts; Washington, D.C.: 2008.

30. Lawrence, A. State sentencing and corrections legislation: 2007 action, 2008 outlook. National Conference of State Legislatures; Denver, Colorado: Jan. 20082008

31. Holtgrave DR, Briddell K, Little E, et al. Cost and threshold analysis of housing as an HIV prevention intervention. AIDS Behav. 2007; 11(6 Suppl):162-6. [PubMed: 17616800]

32. Trenholm, C.; Devaney, B.; Fortson, K.; Quay, L.; Wheeler, J.; Clark, M. Impacts of Four Title V, Section 510 Abstinence Education Programs Final Report April 2007. Mathematica Policy Research, Inc; Princeton, NJ: 2007.

33. United States House of Representatives Committee on Government Reform - Minority Staff Special Investigations Division. The content of federally funded abstinence-only education programs. Washington, D.C.: Dec. United States House of Representatives Committee on Government Reform 20042004

34. Card JJ, Lessard L, Benner T. PASHA: facilitating the replication and use of effective adolescent pregnancy and STI/HIV prevention programs. J Adolesc Health. 2007; 40(3):275, e1-14. [PubMed: 17321429]

35. Santelli J, Ott MA, Lyon M, Rogers J, Summers D. Abstinence-only education policies and programs: a position paper of the Society for Adolescent Medicine. J Adolesc Health. 2006; 38(1): 83-7. [PubMed: 16387257]

36. Williams DR, Costa MV, Odunlami AO, Mohammed SA. Moving upstream: how interventions that address the social determinants of health can improve health and reduce disparities. J Public Health Manag Pract. 2008; 14(Suppl):S8-17. [PubMed: 18843244] 